\title{
Um olhar sobre a Cooperação Sul-Sul em Saúde
}

\author{
An overview of South-South Cooperation on Health
}

José Paranaguá de Santana ${ }^{1}$

${ }^{1}$ Organização Pan-Americana da Saúde, Representação do Brasil. SEN Lote 19, Asa Norte. 70800-400 Brasília DF. jparanagua@hotmail.com

\begin{abstract}
This article presents a brief overview of the meaning of technical cooperation within the United Nations, underscoring the political dimension, i.e. the relationship among States. It also emphasizes the importance of health in this context, using the Americas and Brazil as a benchmark. It illustrates the new paradigm called SouthSouth Cooperation by analyzing an experience in the health field, stressing the triangulation of an intergovernmental agency. In conclusion, it summarizes the arguments that place a given process of international cooperation within the framework of this paradigm.
\end{abstract}

Key words South-South Cooperation, International relations, Health diplomacy, International health, Global health
Resumo $O$ artigo apresenta uma breve revisão sobre o significado da cooperação técnica no seio da ONU, ressaltando a dimensão política, isto é, das relações entre os Estados. Destaca a importância da saúde nesse contexto, tomando como referências a situação das Américas e do Brasil. Analisa uma experiência, na área da saúde, ilustrativa do novo paradigma denominado de Cooperação Sul-Sul, ressaltando a triangulação de uma agência intergovernamental. Conclui resumindo os argumentos que situam um determinado processo de cooperação internacional no marco desse paradigma.

Palavras-chave Cooperação Sul-Sul, Relações internacionais, Diplomacia em saúde, Saúde internacional, Saúde global 


\section{Introdução}

O século XX foi pródigo em avanços científicos e tecnológicos, provocando aumentos da produção e acúmulo de riqueza sem precedentes na história da humanidade. Contudo, o cenário que se apresenta no início do novo século, em termos de usufruto dos benefícios dessa abundância industrial e econômica, é profundamente desalentador para a grande maioria dos habitantes da Terra. $\mathrm{O}$ fator preponderante na gênese dessa situação recai sobre a forma como tem se dado a apropriação da riqueza entre os países e, dentro dos mesmos, entre grupos populacionais. $\mathrm{Na}$ avaliação de Landes ${ }^{1}$, Hoje, o grande desafio e ameaça é o abismo em matéria de riqueza e saúde que separa ricos e pobres. Um abismo crescente, em que a diferença em termos de renda per capita entre a mais rica nação industrial, a Suiça, e o mais pobre país não industrial, Moçambique, é de cerca de 400 para 1. Há 250 anos, esse hiato entre o mais rico e o mais pobre era, talvez, de 5 para $1^{1}$.

Os países do Hemisfério Sul congregam os maiores contingentes de pobres, razão pela qual os reflexos danosos das diferenças econômicas sobre o bem-estar e a saúde das pessoas incidem mais nessa parte da Terra. As evidências compiladas por Benatar ${ }^{2}$ sobre o agravamento da injustiça no mundo são incômodas: a diferença de renda entre os $20 \%$ mais pobres e a mesma proporção dos mais ricos do mundo partiu de um patamar de nove vezes, no início do século passado, cresceu até trinta vezes ao longo de seis décadas e alcançou a cifra de um para oitenta no ano 2000.

A gravidade dessa situação e a preocupação crescente com a progressiva extensão de condições alarmantes de sobrevivência em tantos paí$\mathrm{ses}^{3}$ revigoram o ideal da solidariedade em busca da paz, consagrado com a criação das Nações Unidas. Também provocam a intensificação das propostas de ajuda internacional, cooperação e filantropia que vicejaram nos últimos sessenta anos, na tentativa de minorar os problemas de condições de vida e saúde das populações carentes em todos os cantos do planeta.

O propósito deste ensaio aponta para uma melhor compreensão da natureza dos processos de cooperação entre países. Nesse sentido, apresenta-se inicialmente uma breve revisão sobre o significado desse processo no seio das Nações Unidas, realçando a perspectiva política das relações entre os Estados que integram essa comunidade global. A seguir, destaca-se a importância da área de saúde nesse contexto, tomando como referências a situação do Continente Americano e o caso específico do Brasil. Ante esse pano de fundo, analisa-se uma experiência, no campo da saúde, ilustrativa do novo paradigma denominado de Cooperação Sul-Sul, ressaltando a triangulação de uma agência intergovernamental. À guisa de conclusão, destacam-se os aspectos mais relevantes do caso historiado que caracterizam esse paradigma.

Este artigo é uma contribuição ao projeto de implantação do Núcleo de Estudos sobre Bioética e Diplomacia em Saúde do Centro de Relações Internacionais da Fiocruz/MS e Cátedra Unesco de Bioética da UnB, com apoio da Opas/OMSTC 41.

\section{Cooperação técnica e relações internacionais}

Os países e regiões de todo o mundo apresentam expressivas variações na situação de saúde e condições de vida de suas populações. Contudo, há aspectos comuns, tais como restrições ao acesso e limitações de qualidade do atendimento ou efetividade das ações dos sistemas de saúde. A associação entre dificuldades comuns e interesses compartilhados para enfrentamento das mesmas caracteriza oportunidades de cooperação entre países. Esse desígnio inclui, além da saúde, as diferentes áreas do desenvolvimento nacional, no marco do modelo doutrinário e operacional da cooperação internacional que vem sendo construído paulatinamente no seio das Nações Unidas há várias décadas.

O uso inicial do termo cooperação para o desenvolvimento surgiu com a proposta apresentada pelo Presidente Harry Truman, dos Estados Unidos da América, na abertura da Assembleia Geral da Organização das Nações Unidas (ONU) em 1949. Vinte e três anos depois foi criada a Unidade Especial para Cooperação Técnica entre os Países em Desenvolvimento ${ }^{5}$ - resultado que tem a ver com um processo desencadeado em 1955, com a realização em Bandung ${ }^{6}$, Indonésia, de uma conferência dos países africanos e asiáticos que haviam recém-conquistado sua independência. Naquela oportunidade foi constituído o Grupo Afro-Asiático, que se ampliou com a adesão de países pobres ou em desenvolvimento de outros continentes, formando em 1964 o Grupo dos $77^{7}$. Atualmente, o número de membros desse grupo é bem maior, mas o nome original é mantido por razões históricas, correspondendo praticamente aos países do Sul Global $^{4}$. Embora representem a maior parcela de Estados-membros da ONU, detêm baixo poder 
de decisão nesse colegiado. A criação da referida Unidade Especial constituiu-se, portanto, em estratégia visando influenciar a política de cooperação para o desenvolvimento desencadeada pelo Presidente Truman.

Em setembro de 1978, as delegações de 138 Estados reuniram-se na Argentina para uma Conferência sobre Cooperação Técnica entre Países em Desenvolvimento, e aprovaram o Plano de Ação de Buenos Aires, que representa um marco histórico da doutrina de cooperação no contexto das Nações Unidas. Em dezembro do mesmo ano, a Assembleia Geral desse órgão estabeleceu uma resolução reconhecendo essa proposta como una contribución considerable a la evolución de la cooperación internacional para el desarrollo y al establecimiento del nuevo orden económico internacional'.

Passados vinte e seis anos da Conferência de Buenos Aires, a Assembleia Geral da ONU aprovou nova resolução sobre o tema, Reconociendo que los países en desarrollo tienen la responsabilidad primordial de promover y realizar la cooperación Sur-Sur, que no reemplazaría la cooperación Norte-Sur sino que la complementaria9. Essa norma alterou o nome da Unidade Especial criada em 1972, designando-a de "Cooperação Sul-Sul", realçando nominalmente a dimensão geopolítica do conceito de cooperação. No entanto, a retirada do qualificativo da cooperação "técnica" tem um significado subjacente, pois a nova resolução confere ênfase à cooperação econômica e não apenas técnica, quando esta era explicitada no título anterior e fora reiterada na Conferência de Buenos Aires. Vale registrar ainda a curiosa sentença de que foi apenas uma mudança de nome, sin que ello implique cambio alguno en su mandato o el ámbito de su actividad.

Os aspectos citados apontam para a continuidade da longa trajetória iniciada no seio das Nações Unidas em meados do século passado, em torno de uma definição aparentemente semântica. O largo tempo entre a conferência de Buenos Aires, ou ainda os eventos anteriores a exemplo de Bandung, e a Assembleia Geral em 2004 reflete o processo de transição conceitual e operacional sobre a cooperação internacional, que ocorreu na segunda metade do século passado - processo cuja determinação encontra-se na reconfiguração das relações internacionais, na direção de um novo padrão de relacionamento entre os países situados no Hemisfério Sul. E que representa uma clivagem adicional (sul-sul) à dupla polarização que presidia as relações entre Estados ao longo do século passado, nos eixos geopolíticos leste-oeste (comunismo versus capitalismo) e norte-sul (países desenvolvidos vis-à-vis subdesenvolvidos ou não industrializados). Nessa perspectiva, o significado e a prática da cooperação para o desenvolvimento passariam a modular-se mais pelas relações de identidade entre os países do Sul do que pelas relações de dependência dos países ricos do Norte, além do franco declínio da influência ideológica originária da tensão entre Leste e Oeste que prevaleceu entre o Pós-Guerrra e a queda do Muro de Berlim.

Embora a nova denominação consagrada em 2004 ressalte a conotação geopolítica, seria ingênuo desconhecer a insidiosa prevalência dos interesses dos países mais poderosos na determinação das prioridades e mesmo da condução dos processos de cooperação. Na distância entre a intenção e gesto, nesse caso entre a busca de um novo paradigma da cooperação - Sul-Sul - e a persistência do modelo anterior - Norte-Sul - é que reside a inconformidade que alinha os países do Sul Global nessa renhida negociação com os países mais ricos e poderosos do Hemisfério Norte.

Algumas reflexões emergem nesse percurso de interpretação do termo que inicialmente era "cooperação para o desenvolvimento", tornouse "cooperação técnica entre (ou para) países em desenvolvimento" e foi reinstituído como "Cooperação Sul-Sul". Como reconhecer as vulnerabilidades e os desafios que os países do Sul Global compartilham, sem fazer tábua rasa de suas carências? Como deliberar quais os objetivos e de que modo compartilhar os processos de cooperação para o desenvolvimento? São questões cujo encaminhamento depende de um processo político entre os Estados capaz de gerar consensos sobre como reconhecer e dimensionar vulnerabilidades e desafios, bem como sobre as prioridades que resolvam adotar coletivamente; processos em que não se estabeleçam a priori regras de hegemonia de interesses, mesmo que sob o manto das aparências ou sob o argumento do bem comum.

Outro objeto de reflexão advém do entendimento de que a finalidade geral da cooperação internacional de um país deve alinhar-se à sua política diplomática. Portanto, a esse país cabe estabelecer as prioridades e estratégias setoriais, à luz de orientações que visem a seu fortalecimento no contexto global ou dos blocos regionais ou sub-regionais aos quais se integra. A prática cotidiana da cooperação setorial, especialmente a que se estabelece ou é intermediada pelas agências especializadas das Nações Unidas, atenua a dureza desse pressuposto. É essa, de certo 
modo, a razão de ser dessas agências - neutralizar ou balancear o nacionalismo que impera nas relações diretas entre os países, na busca de um modo de convivência diverso do colonialismo ou da dominação dos interesses dos mais fortes sobre os demais. Contudo, somente a ingenuidade ou o vezo dos "maus samaritanos" ${ }^{10}$ persiste em desconhecer essa ligação orgânica, realçando uma independência que não existe entre os dois processos. A esse respeito, afirma Guimarães ${ }^{11}: a$ politica exterior de um país deve ter como objetivo primordial a defesa e a promoção dos interesses nacionais, sem ilusões quanto à amizade de outros Estados ou quanto a supostas tendências benévolas do sistema internacional. Essa expressão não deve ser interpretada de forma reducionista, pressupondo ou estabelecendo uma contraposição entre interesses nacionais e cooperação ou solidariedade internacionais, pois o autor prossegue argumentando que a política exterior está vinculada, em uma inter-relação ativa, com a política de defesa nacional e com a estratégia geral de desenvolvimento econômico e político ${ }^{11}$.

Em síntese, mudança essencial sobre o significado da cooperação entre Estados-membros das Nações Unidas, do pós-Guerra aos dias atuais, gira em torno da interdependência entre política nacional e cooperação internacional, e esses dois processos, para produzirem resultados genuínos, devem emanar dos próprios Estados. Que as políticas nacionais resultem de decisões dos próprios países seria a polêmica maior, mas o ponto em foco neste ensaio é que também as políticas de cooperação internacional devem ter essa mesma origem para resultar em benefícios concretos e favoráveis aos países, particularmente daqueles com menores recursos de poder econômico, científico e tecnológico. A retórica do sistema internacional adota a premissa de que a cooperação para o desenvolvimento, mesmo tomando em conta a denominação original formulada pelo Presidente Truman em 1949, destina-se a atender aos interesses nacionais. Contudo, a mobilização dos países que fundaram o Grupo Afro-Asiático, e depois o Grupo dos 77, em torno do significado do termo Cooperação Sul-Sul, visa não apenas a objetivos semânticos, mas almeja superar a etapa histórica em que a cooperação para o desenvolvimento, no caso os seus próprios desenvolvimentos nacionais, são moldados e conduzidos de fora para dentro. Em outras palavras, os países do Sul Global pretendem construir projetos de cooperação, inclusive com apoio dos países mais ricos e com intermediação das Nações Unidas, mas que se enqua- drem de verdade em seus próprios desígnios de desenvolvimento.

\section{Saúde e diplomacia}

A importância da saúde nas relações internacionais evoluiu nas Américas de modo similar ao contexto mundial. Naturalmente, há peculiaridades que demarcam a história de cada região do globo e, nesse caso, pelo menos um aspecto merece destaque: ao tempo da criação da Organização Mundial da Saúde, já existia a Oficina Sanitária Pan-Americana, precursora da atual Organização Pan-Americana da Saúde ${ }^{12}$, incorporada ao sistema das Nações Unidas no ato de fundação da $\mathrm{OMS}^{13}$. A existência dessa agência foi a um só tempo resultante e promotora da interação entre os Estados americanos na área da saúde, proporcionando oportunidades de atuação conjunta multilateral (em âmbito continental e sub-regional) e bilateral ${ }^{14-17}$.

É cada vez mais frequente a busca de consensos na definição de política, na captação de recursos financeiros, na promoção de assessorias e assistência técnica ou simplesmente no estabelecimento de redes de colaboração em áreas específicas do campo da saúde - e, aspecto que interessa destacar, a inserção desses processos no contexto de acordos mais amplos de formação de comunidades ou blocos regionais de países. A União das Nações Sul-Americanas (Unasul) ${ }^{18}$ é a ilustração mais recente das relações entre saúde e política externa na região das Américas ${ }^{19}$. Outras experiências, de início anterior e já com extensa lista de resultados, podem ser incluídas no rol de processos sub-regionais de cooperação em saúde, sempre em torno da conformação de blocos de países: Mercosul, Organização do Tratado de Cooperação Amazônica (OTCA), Comunidade Andina de Nações (CAN) e Sistema de Integração Centro-Americana (SICA). História pródiga em dificuldades na formulação de consensos e limitações na obtenção de resultados a curto prazo, mas que reforça a tese da interdependência entre cooperação internacional, política setorial e política externa.

A interação institucional da saúde pública com a chancelaria brasileira tem passado recente, a despeito da tradicional atuação do país no cenário internacional. Exemplos memoráveis não são raros, como o que ocorreu em 1945 na Conferência de São Francisco ${ }^{20}$, quando Geraldo de Paula Souza, médico que integrava a comitiva do Brasil, exerceu atuação-chave nas negociações 
que levaram as delegações dos países fundadores das Nações Unidas a aprovar, por unanimidade e em caráter de urgência, a convocação de uma Conferência Internacional de Saúde que resultou na criação da $\mathrm{OMS}^{21}$.

Uma interpretação para o retardo histórico no reconhecimento da saúde como tema da política externa brasileira foi proposto por Alcázar ${ }^{22}$, destacando três fatores: especialização dessa área de conhecimento, praticamente inacessível ao círculo dos profissionais da diplomacia e sob monopólio dos médicos e sanitaristas; subordinação aos temas econômicos ou do comércio, assuntos familiares à diplomacia tradicional mas infensos à cultura sanitária; baixa expressão institucional da saúde pública no aparato do Estado. O autor também faz uma interessante abordagem sobre a recente e progressiva aproximação entre a política externa e a saúde, considerando quatro indutores dessa tendência: no plano interno, a implantação do Sistema Único de Saúde, o fortalecimento do Ministério da Saúde como interlocutor político e a retaguarda de suas condições orçamentárias ante essas novas funções; e no ambiente externo, a emergência dos temas sociais na agenda das relações internacionais.

No passado, Via-se a saúde, assim como os demais temas sociais, dentro de um enfoque puramente economicista ou mesmo um obstáculo para o desenvolvimento do comércio ${ }^{23}$, situação que se tem modificado visivelmente nos últimos cinco anos. Aponta nessa nova direção o pronunciamento do Presidente da República ${ }^{24}$ na abertura do Congresso Mundial de Saúde Pública em 2006, reconhecendo a importância da saúde na agenda das relações internacionais e a interdependência entre política nacional e cooperação internacional. Significado similar teve a participação do Ministro das Relações Exteriores na Declaração de Oslo, assinada em conjunto com os chanceleres da África do Sul, França, Indonésia, Noruega, Senegal e Tailândia ${ }^{25}$. A visibilidade da saúde pela diplomacia brasileira foi atestada em 2007 pela Agência Brasileira de Cooperação, ao iniciar uma série de publicações sobre a cooperação em áreas específicas: O Brasil, pela exitosa e dinâmica parceria desenvolvida entre o Ministério das Relações Exteriores e o Ministério da Saúde, é um dos principais difusores da cooperação técnica em saúde no mundo em desenvolvimento ${ }^{26}$.

A importância do entrosamento do Ministério das Relações Exteriores com o Ministério da Saúde já fora apontada por Rubarth ${ }^{27}$, questionando a defasagem entre a elevada importância dos temas sociais, particularmente a saúde, na agenda moderna das relações internacionais e a baixa coordenação institucional entre esses dois setores do governo brasileiro. Esse descompasso foi reconhecido em julho de 2005, com o Protocolo de Intenções entre os dois Ministérios, visando aperfeiçoar a coordenação entre o MRE e o MS em matéria de cooperação técnica prestada a países em desenvolvimento, na área de saúde $e^{28}$.

A inserção da saúde na política externa brasileira sedimentou-se quando o Ministro da Saúde empossado em março de 2007 assumiu um compromisso $^{29}$ que, no ano seguinte, passou a constituir um dos sete eixos do programa de ação daquela pasta do Governo: "Mais Saúde - Direito de Todos" 30 .

\section{A modelagem de uma experiência de Cooperação Sul-Sul em Saúde}

A complexa imbricação da cooperação internacional em saúde com a política externa pode ser observada na evolução histórica da cooperação entre uma instituição oficial brasileira, a Fundação Oswaldo Cruz (Fiocruz), e os ministérios da saúde dos Países Africanos de Língua Oficial Portuguesa (Palop). A seguir, intenta-se analisar essa experiência, ressaltando os aspectos que a aproximam do paradigma da Cooperação Sul-Sul, com base nos seguintes critérios: (1) finalidade geral alinhada à política diplomática, favorecendo ou consolidando a inserção do país no contexto global ou dos blocos regionais ou sub-regionais aos quais se integra; (2) aprovação mediante instâncias de deliberação compartilhada, levando em consideração as vulnerabilidades e desafios, bem como prioridades de interesse comum ao conjunto de nações participantes; (3) envolvimento de organismos das Nações Unidas; (4) execução a cargo de instituições nacionais, como promotoras e beneficiárias do desenvolvimento científico e tecnológico inerente ao processo de cooperação.

A partir de iniciativas desencadeadas em meados da década de 1990, originalmente um conjunto de projetos de cooperação de conotação praticamente apenas setorial, consolidou-se um Plano Estratégico de Cooperação em Saúde ${ }^{31}$ no contexto da Comunidade de Países de Língua Portuguesa (CPLP). Em retrospectiva, há nítidos sinais da fluência dos interesses diplomáticos no desenvolvimento desse processo de cooperação internacional em saúde, o que dificilmente se evidenciava há quinze anos. A sequência dos entendimentos políticos e sua resultante atual demons- 
tram que, paulatinamente, buscou-se alinhar tais projetos de cooperação no contexto das prioridades da política externa dos países envolvidos.

Essa agenda originou-se em 1994 com as reuniões de Ministros da Saúde dos países lusófonos $^{27,32}$, tendo a Fiocruz assumido o protagonismo por parte do Brasil. A sequência mais recente dessa agenda teve início com a Reunião Técnica Preparatória da I Reunião dos Ministros de Saúde da CPLP realizada em Praia, Cabo Verde, em novembro de 2007, e um mês depois a reunião promovida pela Fiocruz no Rio de Janeiro, para a elaboração da proposta para essa cooperação internacional. A seguir, na I Reunião dos Ministros da Saúde da CPLP, em abril de 2008, em Cabo Verde, foram aprovadas a Declaração de $\operatorname{Praia}^{33} \mathrm{e}$ a Resolução sobre a elaboração do Plano Estratégico de Cooperação em Saúde da CPLP ${ }^{34}$. A II Reunião dos Ministros da Saúde da $\mathrm{CPLP}^{35}$, em maio de 2009 em Portugal, finalmente aprovou um acordo coletivo de cooperação setorial entre os Estados-membros, o PECS/CPLP ${ }^{31}$.

O apoio da Opas/OMS ao projeto de cooperação da Fiocruz com os Palop foi iniciado no primeiro semestre de 2006, no bojo do Termo de Cooperação $n^{\circ} 41$ (TC 41) $)^{36}$, firmado entre a Opas/OMS e o governo brasileiro, por intermédio do Ministério da Saúde/Fiocruz. Esse suporte tem sido propiciado no âmbito da relação entre a Fiocruz e a Representação da Opas/OMS no Brasil, mas deve ampliar-se incluindo a participação das representações da OMS nos Palop. Além do TC 41, essa triangulação da cooperação tem respaldo na Estratégia de Cooperação Técnica da Opas/OMS com a República Federativa do Brasil 2008-2012: A Cooperação Sul-Sul será potencializada [...] na formulação, execução e avaliação dos programas de cooperação que se executem em forma triangulada entre o Governo Brasileiro, a OMS e os países receptores ${ }^{37}$.

A consolidação da cooperação da Fiocruz com os Palop ocorreu no bojo das relações entre o conjunto de países lusófonos, incluindo Portugal e Timor Leste. O interesse dos países envolvidas nessa convergência também se aplica à participação da Opas/OMS, de modo que foram redirecionadas as tratativas iniciais de âmbito interno, para um arranjo institucional envolvendo essa agência das Nações Unidas com a CPLP, concretizado em janeiro de 2010 num Memorando de Entendimento ${ }^{38}$. Esse é o marco mais recente de uma linha do tempo que interliga os registros históricos da participação da Opas/OMS: o citado discurso de posse do Ministro da Saúde ${ }^{29} \mathrm{em}$ março de 2007 e, dois meses depois, o pronunci- amento do Ministro das Relações Exteriores na sessão de abertura da 60a Assembleia Mundial da Saúde: "O Brasil quer explorar possibilidades de cooperação com organizações internacionais como a OMS"39; os compromissos formalizados em documentos oficiais: a Estratégia de Cooperação Técnica da Opas/OMS-Brasil 2008-2012 $2^{37}$, em agosto de 2007, e em dezembro do mesmo ano, o "Eixo 7 - Cooperação Internacional" no plano de trabalho 2008-2011 do Ministério da Saúde $^{30}$. O TC 41, firmado em dezembro de 2005, representa o marco inicial dessa linha de tempo ${ }^{36}$.

A concepção dessa nova modalidade de cooperação do Brasil com outros países, incentivada com recursos nacionais transferidos para a Opas/OMS, fundamenta-se nas experiências bem-sucedidas de cooperação no contexto nacional $^{40,41}$. A proposta pode ser representada graficamente em formato triangular (Figura 1), em que nos três vértices situam-se os atores do processo de cooperação: (a) Brasil; (b) país(es) contraparte(s) ou comunidades de países $(\mathrm{Pa}-$ lop/CPLP, Unasul etc.); e (c) Opas/OMS:

A estratégia do TC 41 baseia-se no reconhecimento de instituições nacionais como referência para a cooperação internacional nas diferentes áreas da saúde. Os projetos são organizados e operam mediante atuação conjunta entre essas instituições brasileiras e suas congêneres nos demais países. A identificação e a mobilização dessas contrapartes podem ser feitas com apoio das representações da Opas/OMS em cada um deles, sempre com autorização dos governos nacionais. O estatuto de agência intergovernamental e os recursos disponibilizados pelo termo de cooperação constituem uma plataforma jurídica e operacional que contribui para consolidar uma agenda duradoura de cooperação internacional em saúde. Os recursos do TC 41 limitam-se à promoção de atividades de formação de recursos humanos e de formulação e suporte técnico de projetos a cargo de instituições estruturantes dos sistemas de saúde nos países envolvidos. Não correspondem, portanto, a recursos para alavancagem integral de projetos nos países beneficiários.

A instância técnica do Ministério da Saúde envolvida com o TC 41 é a Secretaria de Gestão do Trabalho e da Educação em Saúde, de cujo orçamento advêm os recursos financeiros repassados à Opas. Essa Secretaria integra, juntamente com a Assessoria de Assuntos Internacionais do Gabinete do Ministro e a Presidência da Fiocruz, a Comissão de Programação que estabelece as orientações estratégicas e programáticas do plano de trabalho. A Fiocruz desempenha um 


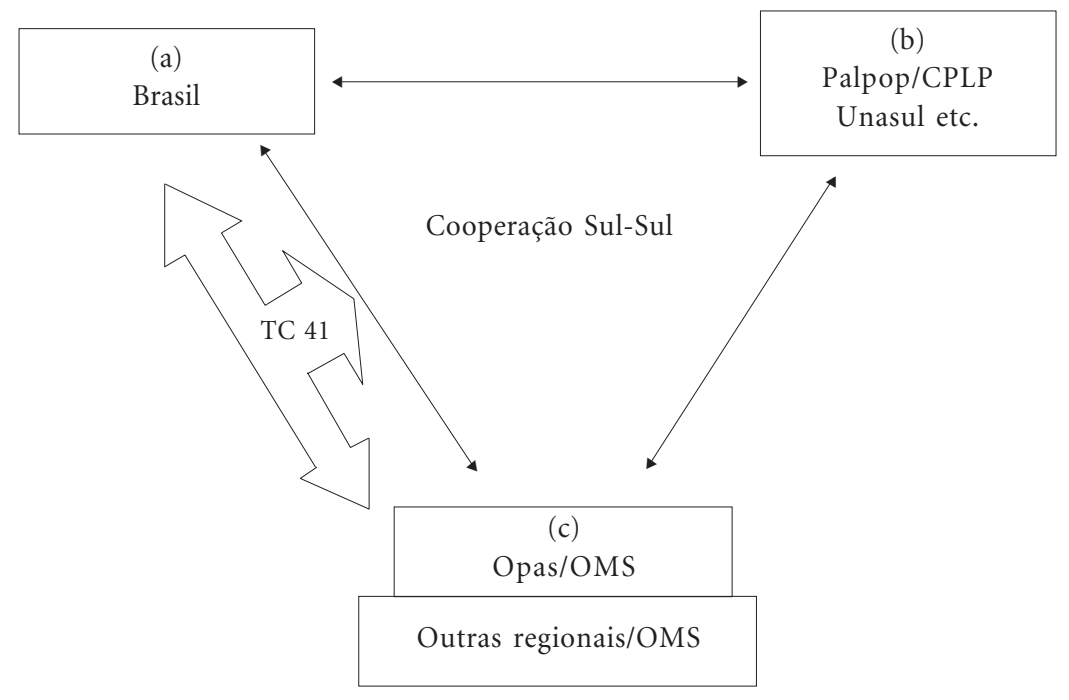

Figura 1. Cooperação Sul-Sul com triangulação da Opas/OMS.

papel expressivo na coordenação do referido termo de cooperação. Além de ser o órgão do Governo Federal que congrega múltiplas funções no campo da saúde pública, sua participação tem como lastro uma larga experiência no cenário internacional. Mas a motivação fundamental para o relacionamento com a Opas/OMS no marco do TC 41 tem a ver com a missão que se atribui à Fiocruz, "como o principal executor da política setorial de cooperação internacional” ${ }^{42}$.

\section{Conclusão}

O propósito deste tópico final é sistematizar os aspectos mais relevantes do caso aqui historiado vis-à-vis às relações internacionais. A discussão sobre o significado da cooperação no seio das Nações Unidas visou delinear o surgimento do novo paradigma denominado de Cooperação SulSul. O marco distintivo apontado neste ensaio encontra-se na relação de interdependência entre cooperação internacional e política externa, processos que devem emanar dos próprios Estados para resultar em benefícios concretos e favoráveis aos países, particularmente daqueles com menores recursos de poder econômico, científico e tecnológico. A nova denominação - Cooperação SulSul-designa, na perspectiva desses países, o apoio para seus próprios desenvolvimentos nacionais, sem subordinação aos interesses dos países mais ricos. Nessa intermediação, torna-se importante a participação das Nações Unidas, como instância de atenuação ou resolução de conflitos potenciais, ocultos ou evidentes, entre os diferentes interesses ou perspectivas de desenvolvimento. A digressão sobre a evolução da saúde na seara da diplomacia permitiu vislumbrar mudanças recentes no cenário histórico em que se desenvolve uma forte e tradicional atividade de cooperação, aparentemente desvestida de razões ou motivações políticas; a novidade refere-se à inclusão dessa antiga e profícua atividade na agenda das relações externas dos países. Desse modo, configurou-se o pano de fundo para apreciação de uma experiência, cujos aspectos de maior destaque, à luz da argumentação desenvolvida neste ensaio, serão resumidos a seguir.

A cooperação entre o Brasil e os Palop revelase expressiva com respeito a sua finalidade geral alinhada à política diplomática, especialmente em vista do enquadramento desse processo nos marcos do PECS/CPLP. Essa leitura denota a característica fundamental desse alinhamento, pois há inequívocos sinais de que os países dessa comunidade têm clara a potencialidade desse processo de cooperação setorial para os respectivos projetos nacionais de política externa. Os países lusófonos despertaram, no fim do século passado, para o reconhecimento de suas identidades como ponto de partida para uma melhor inserção no contexto global ${ }^{43}$. Esse reconhecimento é favorá- 
vel para a interação dentro da própria comunidade e no relacionamento individual ou em conjunto com outros blocos regionais ou sub-regionais de países. A CPLP constitui, portanto, uma plataforma bem delineada para o desenvolvimento de projetos de Cooperação Sul-Sul, congregando países com bases culturais e socioeconômicas que guardam muitos pontos em comum, ainda que apresentem também grandes diferenças em termos de estágio de desenvolvimento econômico, científico e tecnológico.

Os mecanismos de deliberação compartilhada, que foram utilizados no caso da saúde, contam com instâncias já estabelecidas no âmbito geral da comunidade de países, acionados e operados em razão das peculiaridades setoriais, no contexto da matriz de relacionamento já montada, a Secretaria Executiva da CPLP. Nesse arcabouço institucional se reconhecem, analisam e avaliam as vulnerabilidades e os desafios, bem como as prioridades que devem orientar as decisões desse colegiado de nações. Se de um lado isso retarda alguns processos decisórios, de outro garante o estuário em que se debatem e equacionam interesses porventura conflitantes - o que facilita a condução de projetos setoriais, pois as regras gerais do respeito à independência e autonomia de cada Estadomembro encontram-se adrede estabelecidas, além de configurar oportunidade concreta para aferição do postulado de horizontalidade da doutrina de Cooperação Sul-Sul, em contraposição às críticas endereçadas ao paradigma norte-sul.

Com respeito às diferenças de poder econômico, tecnológico e científico, vigentes entre os países ricos do Sul e as nações pobres do Norte, deve-se reconhecer esse tipo de desnível entre o Brasil e cada um dos cinco Palop; e que essas diferenças são suficientemente grandes, a ponto de despertar preocupações quanto ao risco de fatores daí decorrentes prejudicarem as intenções de solidariedade do processo de Cooperação Sul-Sul. Essas circunstâncias reforçam a importância dos mecanismos de gestão da cooperação no contexto da diplomacia, com a interveniência de organizações intergovernamentais. São aspectos que apontam para a consolidação de uma agenda duradoura de cooperação horizontal, ao ampliar as bases institucionais em que se assenta essa agenda, inserida no contexto das relações políticas entre Estados.

Por fim, há o aspecto fundamental da participação das organizações nacionais como promotoras e beneficiárias do desenvolvimento científico e tecnológico inerente ao processo de cooperação. Esse é um tema-chave abordado em diversos documentos do consenso mundial sobre eficácia da ajuda externa, cuja referência mais recente é a Declaração de Acra ${ }^{44}$. No caso em tela, é orientação fundamental do PECS/CPLP que o processo de cooperação vise ao fortalecimento de redes de instituições estruturantes, definidas no Plano como os locais onde a maioria das ações de cooperação será implementada [...] (i) Institutos Nacionais de Saúde Pública, (ii) Escolas Nacionais de Saúde Pública, (iii) Escolas Técnicas em Saúde e (iv) Centros Técnicos de Instalação e Manutenção de Equipamentos.

Esse conjunto de características corrobora a qualificação da experiência apresentada como representativa do novo modelo de Cooperação Sul-Sul, nos termos aqui propostos. Em se tratando de um processo em curso, haveria que identificar parâmetros de coerência entre intenção e resultados, de modo que não se repitam sob nova aparência as limitações ou vícios da velha roupagem da cooperação internacional. Uma criteriosa avaliação dessa experiência constitui a recomendação final deste ensaio. 


\section{Referências}

1. Landes DS. A riqueza e a pobreza das nações: por que algumas são tão ricas e outras tão pobres. Rio de Janeiro: Campus; 1998.

2. Benatar SR, Daar AS, Singer PA. Global health ethics: the rationale for mutual caring. International Affairs 2003; 79(1):107-138.

3. Farmer P. Pathologies of power: health, human rights, and the new war on the poor. Berkley: University of California; 2004.

4. United Nations Development Programme (UNDP). Forging a global south: United Nations day for southsouth cooperation: 19 december 2004. New York: UNDP; 2004.

5. United Nations Development Programme (UNDP). South-South Cooperation: the making of a history. Buenos Aires: UNDP [2005]. [acessado 2010 jan 28]. Disponível em: http://tcdc.undp.org/history.aspx

6. Amin S. Por uma renovação da solidariedade dos povos do Sul: 50० Aniversário da Conferência de Bandung [entrevista a Rémy Herrera]. [acessado 2010 mar 15]. Disponível em: www.mra.org.br/index2. php?option $=$ com_content\&do_pdf $=1 \& i d=177$

7. Group of 77. Four decades of solidarity for the development of the South. New York; 2004. [acessado 2010 jan 28]. Disponível em: www.g77.org/40/undpi.htm

8. United Nations Development Programme (UNDP). The Buenos Aires Plan of Action (BAPA). 1978. [acessado 2010 jan 28]. Disponível em: http://tcdc.undp. org/knowledge_base/bapa_spanish.aspx

9. Organização das Nações Unidas. Cooperación económica y técnica entre los países en desarrollo. New York; 2004. [acessado 2010 fev 06]. Disponível em: www.un.org/es/comun/docs/?symbol=A/RES/58/220

10. Chang HJ. Maus samaritanos: o mito do livre-comércio e a história secreta do capitalismo. Rio de Janeiro: Campus; 2009.

11. Guimarães SP. Desafios brasileiros na era dos gigantes. Rio de Janeiro: Contraponto; 2006.

12. Organização Pan-Americana da Saúde (Opas). La OPS celebra su centenario: informe anual de la Directora, 2003. Washington: Opas; 2003.

13. Organização Mundial da Saúde (OMS). Report of the interim commission to the First World Health Assembly. New York: WHO; 1948.

14. Organização Pan-Americana da Saúde. Cooperação técnica entre países: pan-americanismo no século XXI. In: 25a Conferência Sanitária Panamericana. Washington, D.C.: OPS; 1998.

15. Organização Pan-Americana da Saúde (Opas). Aunar esfuerzos en pro de la salud de las Américas: informe anual de la Directora, 2005. Washington: Opas; 2005.

16. Organização Pan-Americana da Saúde (Opas). Resolución CD48.R16: la salud y las relaciones internacionales: su vinculación con la gestión del desarrollo nacional de la salud. In: $48^{\circ}$ Consejo Directivo. Washington, D.C.; 2008.

17. Organização Pan-Americana da Saúde. Discurso de abertura do Senhor Ministro de Estado da Saúde da República Federativa do Brasil, Dr. José Gomes Temporão. In: $49^{\circ}$ Conselho Diretor. Washington, D.C.; 2009.
18. Unión de Naciones Suramericanas. Consejo de Salud Suramericano. [2010]. [acessado $2010 \mathrm{fev} 16$ ]. Disponível em: www.unasur-salud.org

19. Buss PM. Conselho de Saúde Sul-Americano define ação integrada entre países-membros. Agência Fiocruz de Notícias 2009; 18 set. [acessado $2010 \mathrm{fev}$ 16]. Disponível em: www.fiocruz.br/ccs/cgi/ cgilua.exe $/$ sys $/$ start.htm?infoid $=2859 \&$ sid $=4 \&$ tpl =printerview

20. Organização das Nações Unidas. Historia de Las Naciones Unidas: Conferencia de San Francisco [2009]. [acessado $2010 \mathrm{fev}$ 20]. Disponível em: www.un.org/ es/aboutun/history/sanfrancisco_conference.shtml

21. Szeming S. WHO: from small beginnings [interview]. World Health Forum 1988; 9(1):29-34.

22. Alcazar SLBF. A inserção da saúde na política exterior brasileira. Trabalho apresentado no $48^{\circ}$ Curso de Altos Estudos do Instituto Rio Branco. Brasília: Ministério das Relações Exteriores, Instituto Rio Branco; 2005.

23. Agência Brasileira de Cooperação. Entrevista com o Ministro de Estado da Saúde, Agenor Álvares. ViaABC 2007; mar. p. 23. [acessado 2010 jan 28]. Disponível em: www.abc.gov.br/intranet/Sistemas_ABC/ siteabc/documentos/viaABC-baixa.pdf

24. Brasil. Presidência da República. Discurso do Presidente da República, Luiz Inácio Lula da Silva, por ocasião da cerimônia de abertura do $11^{\circ}$ Congresso Mundial de Saúde Pública e $8^{\circ}$ Congresso Brasileiro de Saúde Coletiva. Brasília: Presidência da República; 2006. [acessado 2010 jan 28]. Disponível em: www.info.planalto.gov.br/download/discursos/ pr1266.doc

25. Ministers of Foreign Affairs of Brazil, France, Indonesia, Norway, Senegal, South Africa, and Thailand. Oslo Ministerial Declaration - global health: a pressing foreign policy issue of our time. The Lancet 2007; 369(9570):1373-1378.

26. Agência Brasileira de Cooperação. A parceira entre o Itamaraty e o Ministério da Saúde. ViaABC 2007; mar. p. 2. [acessado 2010 jan 28]. Disponível em: www.abc.gov.br/intranet/Sistemas_ABC/siteabc/ documentos/viaABC-baixa.pdf

27. Rubarth EO. A diplomacia brasileira e os temas sociais: o caso da saúde. Brasília: Instituto Rio Branco; 1999.

28. Brasil. Ministério das Relações Exteriores. Ministério da Saúde. Protocolo de Intenções entre o Ministério das Relações Exteriores e Ministério da Saúde. Brasília: Ministério da Saúde; 25 jul. 2005.

29. Brasil. Ministério da Saúde. Discurso de posse do Dr. José Gomes Temporão no cargo de Ministro da Saúde em 19 de março de 2007. Brasília: Ministério da Saúde; 2007. [acessado 28 jan. 2010]. Disponível em: http://portal.saude.gov.br/portal/saude/visualizar_ texto.cfm?idtxt $=25744$

30. Brasil. Ministério da Saúde. Mais saúde: direito de todos: 2008-2011. 2a ed. Brasília: Ministério da Saúde; 2008. 
31. Comunidade dos Países de Língua Portuguesa. Plano Estratégico de Cooperação em Saúde da CPLP (PECS/ CPLP): 2009-2012. [Estoril]: CLPL; 2009. [acessado 26 jan. 2010]. Disponível em: www.cplp.org/Admin/ Public/DWSDownload.aspx?File $=\% 2$ fFiles $\% 2$ fFiler $\%$ 2 fcplp $\% 2$ fredes $\% 2$ fsaude $\% 2$ fIIReuniaoEstoril $\% 2 f$ DOC5_PECS2009-2012_15Maio.pdf

32. Ata Final do $2^{\circ}$ Encontro dos Ministros da Saúde dos Países de Língua Oficial Portuguesa. Rio de Janeiro: [s.n.]; 12 ago. 1994.

33. Comunidade dos Países de Língua Portuguesa. Declaração da Praia. [Apresentada na I Reunião de Ministros da Saúde da Comunidade dos Países de Língua Portuguesa]; 2008 11-12 abr.; Praia, Cabo Verde. [acessado 2008 abr 27]. Disponível em: www.cplp.org/Admin/Public/DWSDownload.aspx? File $=\% 2$ fFiles $\% 2$ fFiler $\% 2$ fcplp $\% 2$ fredes $\% 2$ fsaude $\% 2 \mathrm{f}$ ReuniaoPraia\%2fDeclaracaoPRAIA6_FINAL.pdf

34. Comunidade dos Países de Língua Portuguesa. Resolução sobre a elaboração do Plano Estratégico de Cooperação em Saúde da CPLP. [Apresentada na I Reunião de Ministros da Saúde da Comunidade dos Países de Língua Portuguesa; 2008 11-12 abr.; Praia, Cabo Verde. [acessado 2010 fev. 06]. Disponível em: www.cplp.org/Admin/Public/DWSDownload.aspx? File $=\% 2$ fFiles $\% 2$ fFiler $\% 2$ fcplp $\% 2$ fredes $\% 2$ fsaude $\% 2 f$ ReuniaoPraia\%2fPlanoEstrat\%ef\%bf\%bdgico.pdf

35. Comunidade dos Países de Língua Portuguesa. Declaração do Estoril [Estoril]: CLPL; 2009. [acessado 2010 jan. 26]. Disponível em: http://www. cplp.org/ Admin/Public/DWSDownload.aspx?File= $\% 2$ fFiles $\% 2$ fFiler $\% 2$ fcplp $\% 2$ fredes $\% 2$ fsaude $\% 2 f I I$ ReuniaoEstoril\%2fDeclarEstorilFINAL_15Maio.pdf

36. Brasil. Ministério da Saúde. Extrato do 41º Termo de Cooperação e Assistência Técnica ao ajuste complementar. Diário Oficial da República Federativa do Brasil 2006; 10 jan. 2006; Seção 3.

37. Organização Pan-Americana da Saúde (Opas). Estratégia de cooperação técnica da OPAS/OMS com a República Federativa do Brasil, 2008-2012. Brasília: Opas; 2007.
38. Memorando de entendimento entre a Organização Mundial da Saúde e a Comunidade dos Países de Língua Portuguesa para apoiar a execução do Plano Estratégico de Cooperação em Saúde da CPLP. Lisboa; 2010. 6 jan. [acessado 15 mar. 2010]. Disponível em: http://new.paho.org/bra/index.php?option= com_docman\&task=doc_download\&gid=915\&Itemid

39. Amorim CLN. Discurso do Ministro Celso Amorim na 60a Assembleia Mundial de Saúde; 2007. [acessado 2010 jan. 28]. Disponível em: www. mre.gov.br/portugues/politica_externa/discursos/ discurso_detalhe3.asp?ID_DISCURSO=3092

40. Pires-Alves FA, Paiva CHA. Recursos críticos: história da cooperação técnica Opas-Brasil em recursos humanos para a saúde (1975-1988). Rio de Janeiro: Editora Fiocruz; 2006.

41. Castro JL. Protagonismo silencioso: a presença da Opas na formação de recursos humanos em saúde no Brasil. Natal: Observatório RH NESC/UFRN, Ministério da Saúde, Opas; 2008.

42. Brasil. Ministério da Saúde. Fundação Oswaldo Cruz. Relatório de atividades: 2005-2008. Rio de Janeiro: Fiocruz; 2009.

43. Comunidade dos Países de Língua Portuguesa. Histórico: como surgiu? [S.1.]: CPLP; 2009. [acessado 2010 fev. 25]. Disponível em: www.cplp.org/Default. aspx?ID $=45$

44. Agenda para ação de Acra. In: $3^{\circ}$ Forum de Alto Nível sobre Eficácia da Ajuda; 2 a 4 set. 2008; Acra, Gana; 2008. [acessado 2010 fev. 20]. Disponível em: www.ipad.mne.gov.pt/images/stories/APD/FINALAAA-in-Portuguese\%5B1\%5D.pdf

Artigo apresentado em 29/03/2010

Aprovado em 13/05/2010

Versão final apresentada em 20/06/2010 